\title{
BASES TEÓRICO-PEDAGÓGICAS DO ATENDIMENTO EDUCACIONAL ESPECIALIZADO EM DUAS REDES MUNICIPAIS DE ENSINO NO BRASIL
}

\author{
THEORETICAL-PEDAGOGICAL BASES OF THE SPECIALIZED \\ EDUCATIONAL ASSISTANCE IN TWO MUNICIPAL EDUCATION \\ NETWORKS IN BRAZIL
}

\section{BASES TEÓRICO-PEDAGÓGICO DE LA ATENDIMIENTO EDUCACIONAL ESPECIALIZADO EN DOS REDES MUNICIPALES DE EDUCACIÓN EN BRASIL}

IVONe RodRigues dos SANTOS ${ }^{1}$

RéGis Henrique dos Reis Silva ${ }^{1}$ Universidade Estadual de Campinas (UNICAMP), Campinas/SP - Brasi ${ }^{1}$

\begin{abstract}
Resumo Este artigo apresenta e discute as bases teórico-pedagógicas que subsidiam as orientações para a organização do Atendimento Educacional Especializado (AEE) em duas redes públicas municipais de ensino, sendo uma no Estado de Goiás e outra no Estado do Paraná. Inicialmente, apontamos as implicações das teorias educacionais que orientam a atual política educacional na perspectiva inclusiva. Em seguida, subsidiados pelos pressupostos teórico-filosóficos da Pedagogia Histórico-Crítica e da Psicologia Histórico-Cultural, verificamos que os municípios articulam de forma distinta a implementação do AEE. Fundamentado por um conjunto de bases teóricas que nomeamos de miscelânea pragmáti$c a$, constatamos que o AEE é interpretado como estratégia para compensar deficiências de diferentes ordens, limitando-se a um quadro naturalizante de estruturação do ser humano, ou, de outro modo, busca formas de promover o desenvolvimento humano, sem perder de vista sua especificidade pedagógica, o que denominamos de miscelânea crítica. Assim, embora existam limites nas ações desenvolvidas pelos municípios diante das políticas sociais e econômicas, em âmbito nacional e mundial, a compreensão dos educadores/as acerca da teoria educacional como orientadora da práxis educativa é um elemento fundamental do ato
\end{abstract}


educativo em uma perspectiva crítica e superadora da realidade da educação brasileira nas primeiras décadas do século XXI.

Palavras-chave: Bases teórico-Pedagógica; Atendimento Educacional Especializado; Pedagogia Histórico-Crítica; Psicologia Histórico-Cultural.

Abstract This article presents and discusses the theoretical and pedagogical bases that support the guidelines to Specialized Educational Assistance (AEE) in two municipal public education networks, one in the State of Goiás and another in the State of Paraná. Initially, we pointed out implications of the educational theories that guide current educational policy in inclusive perspective. Then, subsidized by theoretical-philosophical assumptions to Historical-Critical Pedagogy and Historical-Cultural Psychology, we find that these municipalities articulate the implementation of ESA differently. Based on by theoretical bases mentioned of the pragmatic miscellany, we find that AEE is interpreted as strategy to compensate deficiencies of different orders, limited to a naturalizing human structuring or, alternatively, search promote the human development, without lose its pedagogical specificity, what we named criticism miscellaneous. Then, although there are limits in actions developed by these municipalities about the socials and economics policies, nationally and worldwide, teachers understanding about educational theory as guiding the educational praxis is a fundamental element of the educational act in a critical and overcoming perspective to Brazilian education reality in the first decades of the 21 st century.

Keywords: Theoretical-Pedagogical bases; Specialized Educational Assistance; Historical-Critical Pedagogy; Historical-Cultural Psychology.

RESUMEN Este artículo presenta y discute las bases teórico-pedagógicas que subsidian las orientaciones para la organización del Atendimiento Educacional Especializado (AEE) en dos redes de educación pública municipal, en el estado de Goiás y en el estado de Paraná. Inicialmente, apuntamos las implicaciones de las teorías educacionales que orientan la actual política educacional en la perspectiva inclusiva. Enseguida, orientados por los presupuestos teórico-filosóficos de la Pedagogía Histórico-Crítica y de la Psicología Histórico-Cultural, verificamos que los municipios articulan de forma distinta la implementación del AEE. Fundamentado por un conjunto de bases teóricas que nombramos de miscelánea pragmática constatamos que el AEE es interpretado como una estrategia para compensar las discapacidades de diferentes órdenes, limitándose a un cuadro naturalizante de estructuración del ser humano, o, de otro modo, busca maneras de promover el desarrollo humano, sin perder de vista su especificidad pedagógica, lo que denominamos de miscelánea crítica. Así, aunque, haya límites en las acciones desarrolladas por los municipios ante las políticas sociales e económicas, en el ámbito nacional y mundial, la comprensión de los educadores acerca de la teoría educacional como orientadora de la praxis educativa es un elemento 
fundamental del acto educativo en una perspectiva crítica y superadora de la realidad de la educación brasileña en las primeras décadas del siglo XXI.

Palabras clave: Bases teórico-pedagógicas; Atendimiento Educacional Especializado; Pedagogía Histórico-Crítica; Psicología Histórico-Cultural.

\section{FUNDAMENTOS TEÓRICO-PEDAGÓGICOS DA POLÍTICA NACIONAL DE EDUCAÇÃo ES- PECIAL NA PERSPECTIVA INCLUSIVA}

No Brasil, as diferentes concepções de desenvolvimento humano e aprendizagem sempre estiveram vinculadas aos conflitos de interesses que permeiam a sociedade em cada momento histórico. Nesse sentido, a história da pedagogia é marcada pelas diversas posições teóricas, o que acaba delineando, de forma diferenciada, a organização dos processos de escolarização, conforme sintetizam Saviani e Duarte (2010, p. 430-431):

Especialmente, ao longo do século XX, o pensamento pedagógico foi atravessado por tendências contrapostas, a disputar a hegemonia do campo educativo. Pedagogia conservadora versus pedagogia progressista, pedagogia católica (espiritualista) versus pedagogia leiga (materialista), pedagogia autoritária versus pedagogia libertadora, pedagogia passiva versus pedagogia ativa, pedagogia da essência versus pedagogia da existência, pedagogia bancária versus pedagogia dialógica, pedagogia teórica versus pedagogia da prática, pedagogia do ensino versus pedagogia da aprendizagem e, dominando todo o panorama e, em certo sentido, englobando as demais oposições, pedagogia tradicional versus pedagogia nova (grifos do autor).

No contexto específico da Educação Especial/Inclusiva, a compreensão das bases teórico-pedagógicas que subsidiam as práticas educacionais ganha destaque a partir da década de 1990, devido às ações do governo brasileiro de alinhamento das políticas educacionais com as mudanças no sistema do Capital e de seu metabolismo social, o que foi denominado de Reforma do Estado e da Educação (KASSAR, 2011; SILVA, 2013).

Desde então, as reformas realizadas no âmbito do Estado ou na especificidade da área educacional vêm sendo organizadas pelo governo como parte do que tem sido denominado de política de inclusão. A partir desse período, é possível identificarmos alguns eixos que constituem a filosofia da atual política brasileira em relação aos encaminhamentos apontados para o campo da Educação Especial/Inclusiva.

Ao consubstanciar-se nas recomendações internacionais e nos princípios inclusivistas, ${ }^{1}$ preconizados pelas conferências de Educação para Todos (DECLARAÇÃO DE JOMTIEN, em 1990) e sobre Necessidades Educacionais Especiais (DECLARAÇÃO DE SALA-

1 O princípio fundamental dessa Linha de Ação é de que as escolas devem acolher todas as crianças, independentemente de suas condições físicas, intelectuais, sociais, emocionais, linguísticas ou outras. Devem acolher crianças com deficiência e crianças bem dotadas; crianças que vivem nas ruas e que trabalham; crianças de populações distantes ou nômades; crianças de minorias linguísticas, étnicos ou culturais e crianças de outros grupos e zonas desfavorecidas ou marginalizados (BRASIL, 1994, p. 3). 
MANCA, em 1994), das quais o Brasil foi signatário, a política educacional brasileira passou a disseminar valores que vinculam a educação, por meio de um discurso inclusivo e filiado em bases liberais e economicistas, aos conceitos de direitos humanos, crescimento econômico e desenvolvimento social do país, apontando para a incorporação da Teoria do Capital Humano² na Educação Especial.

Em decorrência desses ajustes estruturais e parcerias internacionais, preconizados pelos princípios inclusivistas, as bases teórico-pedagógicas que fundamentam a estruturação das ações para o campo educativo se remodelaram, contribuindo para o crescimento dos vários modismos na educação e para a propagação de novas técnicas e estratégias pedagógicas. Os referidos modismos são desdobramentos das primeiras pedagogias burguesas (escola tradicional, escola nova e educação tecnicista), surgindo atualmente com novas roupagens, chamando-se de pedagogia das competências, pedagogia do professor reflexivo, construtivismo, pedagogia empreendedora, pedagogia dos projetos, multiculturalismo, entre outros. Para Duarte (2000) e Saviani (2013a), essa refuncionalização da teoria do capital humano se faz presente nos prefixos neo e pós, dando origem a expressões como neoconstrutivismo, pós-estruturalismo, neoescolanovismo, neotecnicismo e pós-construtivismo, por meio do qual o antigo é recriado e condicionado à nova lógica imposta pelo Capital.

Contudo, por esse viés, os projetos de ensino não apresentam intencionalidade em defender o trabalho educativo como uma produção direta e intencional, preocupado em descobrir as formas mais adequadas de promover o desenvolvimento humano. Ao contrário, pelo fato de algumas abordagens considerarem apenas o ser humano em abstrato, desvinculado de um engajamento contextual, e outras enfatizarem apenas o momento histórico, destacando os seus condicionantes sócio-político-econômicos, as perspectivas teóricas acabam contribuindo para o aumento de uma marginalização em relação aos processos de escolarização.

Frente a esse novo paradigma educativo, a Educação Especial, entendida em nossa legislação de ensino como modalidade educacional responsável pela educação de pessoas com deficiências (compreendidas como os que apresentam deficiência física, visual, auditiva e intelectual); altas habilidades/superdotação e transtornos globais do desenvolvimento (BRASIL, 2008), vem sofrendo alterações relevantes na medida em que as atuais orientações trazem implicações que incidem sobre a prática educativa e sobre os procedimentos de gestão. As novas definições abrangem tanto os aspectos relacionados aos locais e metodologias da educação disponibilizada, quanto ao que se refere ao reforço das responsabilidades das secretarias municipais, estaduais ou órgãos equivalentes para o processo de implementação, organização e acompanhamento dessa política.

2 A referida concepção se desenvolveu a partir das décadas de 1950 e 1960, tornando-se orientação oficial no Brasil sob a forma da pedagogia tecnicista. Contudo, o significado que veio a prevalecer a partir da década de 1990 deriva de uma lógica voltada para a satisfação de interesses privados, guiada pela ênfase nas capacidades e competências que cada pessoa deve adquirir no mercado educacional para atingir uma melhor posição no mercado de trabalho. Nesse cenário, é o indivíduo que terá de exercer sua capacidade de escolha, visando adquirir os meios que lhe permitam ser competitivo no mercado de trabalho (SAVIANI, 2005; 2013a). 
A projeção das normativas para esse atendimento encontra-se melhor sistematizada a partir do ano de 2008, com a elaboração do documento Política Nacional da Educação Especial na Perspectiva da Educação Inclusiva (BRASIL, 2008), cujos princípios elegem o Atendimento Educacional Especializado (AEE), realizado em Salas de Recursos Multifuncionais (SRM), ${ }^{3}$ como principal suporte para as necessidades específicas dos educandos público-alvo da Educação Especial. O atendimento realizado nesse espaço é apresentado como sendo a solução para o problema da marginalidade histórica vivenciada pelo público-alvo da educação especial na perspectiva inclusiva, conforme podemos evidenciar no que está disposto no manual de orientação do programa de implementação de salas de recursos multifuncionais:

\begin{abstract}
A implantação das Salas de Recursos Multifuncionais nas escolas comuns da rede pública de ensino atende à necessidade histórica da educação brasileira, de promover as condições de acesso, participação e aprendizagem dos alunos público-alvo da educação especial no ensino regular, possibilitando a oferta do atendimento educacional especializado, de forma não substitutiva à escolarização (BRASIL, 2010a, p. 3).
\end{abstract}

Contudo, ao ser o mediador dessa política, os gestores educacionais encontram-se permeados de inúmeras responsabilidades e dificuldades que antecedem e acompanham a implantação desse atendimento. Verifica-se, por meio das orientações legais (BRASIL, 2008, 2009, 2010a, 2010b, 2011), que a projeção da ação educacional do AEE envolve o interesse: dos mais pobres; dos profissionais com formações específicas; da comunidade escolar; de órgãos intersetoriais; e dos docentes. Logo, chamamos a atenção para a construção ideológica expressa neste discurso. O que se percebe é o ideário da reforma educacional atribuindo aos sistemas de ensino, às escolas e aos professores um protagonismo fundamental, como se as mazelas evidenciadas na educação estivessem sob suas responsabilidades (SHIROMA; MORAES; EVANGELISTA, 2007), de forma que a possibilidade de mudança não é vista como sendo necessária uma intervenção e transformação na forma de organização social injusta na qual está assentado o modo de produção econômico do país.

Tendo em vista o atual contexto e suas possíveis interferências em relação às (im) possibilidades que a centralidade dessas políticas apresenta para a capacidade das redes de educação em organizar, planejar e estruturar um ensino que ultrapasse o determinismo biológico, buscamos apreender teoricamente as bases teórico-pedagógicas que subjazem à organização desse atendimento na política nacional e nos sistemas de ensino, discutindo os limites e as possibilidades destas no âmbito administrativo-pedagógico de implementação da política de educação especial na perspectiva inclusiva.

3 Essas salas foram implantadas como parte de um programa específico do Ministério da Educação - O Programa de Implantação de Salas de Recursos Multifuncionais, que tem como objetivo apoiar os sistemas de ensino na implantação de salas com materiais pedagógicos e de acessibilidade, para a realização do atendimento educacional especializado. 
Tal preocupação é justificada, porque, historicamente, a educação tem sido considerada como um instrumento de mediação em uma sociedade de classes (SAVIANI, 2012a; SILVA, 2013), podendo, assim, de acordo com sua fundamentação teórica, deixar de exercer sua função política de socialização do conhecimento, para dissolver-se em práticas pedagógicas que visam à manutenção de um quadro social e educacional de discriminação e exclusão.

Desse modo, dentro do escopo proposto, trata-se de uma investigação realizada em dois municípios brasileiros, um localizado no Estado de Goiás e outro no Estado do Paraná. A seguir, recuperamos os pressupostos teórico-metodológicos que subsidiaram a pesquisa.

\section{Pressupostos teórico-metodológico}

As diretrizes da política educacional brasileira não estabelecem, explicitamente, o direcionamento teórico e/ou orientação pedagógica para a ação educativa no atendimento especializado. A escolha explícita, ou não, de determinado referencial teórico para subsidiar e orientar a prática educativa, apontando uma concepção pedagógica que promova um ato intencional na organização do atendimento escolar, bem como, no processo de gestão para a implementação, acompanhamento e formação de equipes responsáveis para estruturar o serviço da Educação Especial/Inclusiva nos sistemas de ensino, estão sob as responsabilidades das secretarias municipais, estaduais ou órgãos equivalentes (BRASIL, 2009), podendo realizá-las conforme suas possibilidades e concepções de gestão.

\section{LóCUS DA PESQUISA E INSTRUMENTOS DE INVESTIGAÇÃO}

Diante do quadro exposto, as orientações pedagógicas ao Atendimento Educacional Especializado nos sistemas de ensino apresentam possibilidades de serem fundamentadas a partir de perspectivas distintas, ou seja, atendendo essencialmente ao que está disposto nas orientações legais, e desse modo, priorizando as questões pragmáticas e operacionais, ou, adotando determinada corrente teórico-filosófica para a fundamentação dos seus currículos, de forma que, mesmo seguindo as orientações legais não se esvazia da sua especificidade pedagógica. Parte da compreensão de que a interpretação do fenômeno educacional deriva de uma tomada de posição epistemológica em relação ao sujeito e ao meio. Tal proposição nos exigiu, como interesse metodológico, considerarmos, como campo de investigação, municípios brasileiros que apresentassem em seus planos de ensino orientações teórico-metodológicas diferentes. Delineamos, portanto, como lócus para esta pesquisa, uma rede municipal de ensino localizada no Estado de Goiás e outra no Estado do Paraná.

Contudo, inicialmente, é oportuno ressaltarmos que temos a ciência que os municípios pesquisados, estão localizados em Estados brasileiros com projetos bem distintos em relação à implantação de políticas de atendimento ao público-alvo da Educação Especial/ Inclusiva. Goiás incentiva a inclusão escolar pela via da matrícula em classe comum e o Estado do Paraná tem uma política de reconhecimento de instituições especializadas como escolas de educação básica na modalidade especial. Não obstante, entendemos que tal diferenciação na política de atendimento reforça e explicita a necessidade de discutir, de 
forma concreta, o movimento real da implementação da política de educação especial na perspectiva inclusiva. Sem desconsiderar as especificidades regionais e as concepções de gestão de cada rede de ensino, esta pesquisa não intencionou uma descrição pormenorizada de determinado contexto e, sim, evidenciar o movimento real da sociedade, interpretada no contexto histórico.

Posto isso, a escolha pelo município do Estado de Goiás justifica-se pelo fato do município não caracterizar, explicitamente, no seu plano de educação, uma concepção pedagógica específica para a estruturação da proposta de educação inclusiva, atendendo essencialmente ao que está disposto nas orientações legais. Já, o município do Estado do Paraná justifica-se por apresentar ações elaboradas pela Secretaria Municipal de Educação no campo da Educação Especial, desde o ano de 1978, fundamentadas por um direcionamento teórico-metodológico que defende uma concepção de sociedade, educação e desenvolvimento humano que considera o caráter histórico do ser humano. Entendermos que o tempo de trabalho que o município vem desenvolvendo no campo da educação especial/inclusiva proporcionaria boas condições de análise acerca dos objetivos, organização, operacionalização, acompanhamento e avaliação da política inclusiva.

Desse modo, a investigação caracterizou-se como uma pesquisa bibliográfico-documental e de campo, tendo como procedimentos para coleta e registro de dados o fichamento bibliográfico-documental e a entrevista semiestruturada, gravada em áudio, com gestores e professores responsáveis pela operacionalização e realização das políticas públicas de educação inclusiva para o AEE nos municípios em estudo.

\section{Sujeitos da pesquisa}

Por entender que as visões e concepções se diferem dependendo da posição e/ou função que o sujeito realiza, optamos por envolver a participação de gestores e professores. Cientes de que as especificidades que permeiam a estruturação de cada segmento educacional influenciam na complexidade da prática pedagógica do professor no AEE e, partindo da realidade apresentada pelo município do Estado de Goiás, que oferece o AEE na educação infantil, ${ }^{4}$ elencamos como critérios para seleção das unidades escolares duas instituições que oferecem o AEE na educação infantil e duas escolas que oferecem o AEE nos anos iniciais e finais $\left(1^{\circ}\right.$. ao $9^{\circ}$. ano) do ensino fundamental. Contudo, como os municípios apresentaram formas de organização diferenciadas, tivemos a participação dos seguintes sujeitos:

- Município do Estado de Goiás: 01 coordenadora do setor responsável pelo acompanhamento da política inclusiva na Secretaria Municipal de Educação e 02 professoras que realizam o AEE (uma na Educação Infantil e outra no Ensino fundamental, atendendo alunos do $1^{\circ}$. ao $9^{\circ}$. ano).

4 Em observância às orientações apresentadas no documento "Política Nacional de Educação Especial na Perspectiva da Educação Inclusiva" (BRASIL, 2008) e no "Plano Nacional de Educação" (BRASIL, 2014), para que os sistemas de ensino fomentem até o prazo de vigência do atual PNE, a oferta desse atendimento em todas as etapas e modalidades da educação básica, o município optou por oferecer, no ano em que esta pesquisa foi realizada, o atendimento especializado em SRM intencionando identificar os limites e as possibilidades do serviço a fim de organizar as políticas para o atendimento. 
- Município do Estado do Paraná: 01 coordenadora do setor responsável pelo acompanhamento da política inclusiva na Secretaria Municipal de Educação; 01 coordenadora que acompanha especificamente o trabalho realizado nas Salas de Recursos Multifuncionais no município e 02 professoras que realizam o AEE no Ensino Fundamental anos iniciais $\left(1^{\circ}\right.$. ao $5^{\circ}$. ano $)$.

\section{Procedimentos de análises das informações}

Para a análise dos documentos legais, além das orientações fundantes da política educacional, recorreremos aos documentos oficiais que normatizam a política da Educação Especial na Perspectiva Inclusiva, principalmente os documentos orientadores da operacionalização do Atendimento Educacional Especializado, sendo eles: Política Nacional de Educação Especial na Perspectiva da Educação Inclusiva de 2008, a Resolução no .4 de 2 de outubro de 2009, a Nota Técnica $\mathrm{n}^{\circ}$. 11, de 7 de maio de 2010, o Decreto ${ }^{\circ} .7 .611$, de 17 de novembro de 2011, e o atual Plano Nacional de Educação - PNE (BRASIL, 2014). No âmbito municipal, recorremos, prioritariamente, às diretrizes gerais de organização e funcionamento das duas redes municipais em estudo e aos respectivos planos de atendimentos da educação especial na perspectiva da educação inclusiva.

A extensão da análise, obtida a partir dos documentos levantados e das entrevistas realizadas, contemplou os âmbitos político, técnico-científico, pedagógico e administrativo, conforme prevê o Parecer CNE/CEB 17/2001 (BRASIL, 2001a), ${ }^{5}$ documento que normatiza o serviço realizado pela Educação Especial nas redes de ensino. Ressaltamos a ciência da indissociabilidade existente entre os âmbitos, no entanto, esta escolha foi por nós considerada como uma das possibilidades para melhor compreender o objeto, além de contribuir para conferir, de forma mais acentuada, a complexidade dos fatores que envolvem a implementação dessa política inclusiva nas redes de ensino.

No âmbito político, investigamos e discutimos a forma de organização e estruturação da atual política inclusiva nas duas redes de ensino, contemplando informações sobre: a) A proposta político-pedagógica da SME; b) Os alunos atendidos; e c) O financiamento. No âmbito técnico-científico, a partir das orientações exibidas pelo referido documento, apresentamos e discutimos a categoria: a) Do perfil e da formação de professores para atuar na educação especial e no AEE. Para discutir as ações delineadas no âmbito pedagógico emergiram as seguintes divisões: a) Da identificação e encaminhamento para o serviço da educação especial; e b) Da organização da prática pedagógica do AEE na sala de recurso multifuncional. E, para responder aos desafios no âmbito administrativo, foram contempladas as seguintes informações: a) Do setor responsável pela educação especial; b) Da acessibilidade; c) Da ampliação do compromisso político com a educação inclusiva; e d) Da organização das redes de apoio.

5 Lembramos que a definição de educação especial presente neste documento, bem como, a orientação sobre o serviço realizado por essa modalidade nos sistemas de ensino, está em consonância com a Resolução CNE/CEB nº. 02/2001 (BRASIL, 2001b) por ser anterior à publicação da PNEE-EI (BRASIL, 2008). Desse modo, em nossa análise, consideramos a estruturação prevista em cada âmbito, porém, atendendo à redefinição do público e serviço a ser realizado de acordo com as orientações da atual política inclusiva (BRASIL, 2008, 2009, 2010a, 2010b, 2011). 
A opção por esses procedimentos nos auxiliou na compreensão da nossa problemática de pesquisa na sua totalidade, pois eles se referem aos diversos modos em que apreendemos a realidade, não intencionando, portanto, uma análise individual dos dados, desvinculados do contexto em que estão inseridos. Entendemos que:

\begin{abstract}
A heurística do método não está na sua mecânica garantida pelo cuidado registrado da separação das partes e a posterior reconstrução. Está na possibilidade de conhecer o artefato no seu interior e revelar seu funcionamento para, com base nesse conhecimento, elaborar melhores artefatos, modificando suas partes, compactando algumas delas e aprimorando seu funcionamento (SÁNCHEZ-GAMBOA, 2013, p. 63).
\end{abstract}

Os resultados obtidos nas análises desses dados, bem como, dos documentos investigados e das entrevistas realizadas possibilitaram a identificação dos pressupostos teóricos que fundamentam a organização do trabalho da educação especial em cada rede de ensino e suas implicações para a prática administrativo-pedagógica, conforme apresentamos a seguir.

\title{
MiscelâneA PRAGMÁticA E MiSCELÂNEA CRÍTICA - LIMITES E POSSIBILIDADES
}

O atual cenário do setor produtivo norteado, principalmente nos últimos 20 anos, por políticas neoliberais, afinadas com as exigências da mundialização da economia e associado a relações de poder que derivam de uma lógica voltada para a satisfação de interesses privados (SAVIANI, 2013a), tem avançado a cada dia, canalizando não apenas as funções manuais para a máquina, como também as operações intelectuais. Percebe-se que esse novo panorama exerce forte influência sobre o sistema educativo. A forma de produção e do mercado tem orientado os modelos pedagógicos, responsáveis pela formação dos professores, a desenvolverem competências profissionais, intelectuais e sociais, direcionadas a preparar o sujeito às necessidades do próprio processo produtivo, exigindo da educação e da escola uma mudança de paradigma em relação a sua função política de socialização do conhecimento, resultando, em seu limite, numa desvalorização dos processos de ensino e em uma crescente ênfase na fragmentação de ações, reduzindo a educação do ser humano, tendo ele deficiência ou não, a conhecimentos "básicos" de língua portuguesa e matemática.

Não obstante, temos a compreensão de que a organização dos processos de ensino-aprendizagem para ser adequadamente compreendido exige que se pensem os problemas da educação numa perspectiva radical, rigorosa e de conjunto (SAVIANI, 2012b). Assim, a concepção teórica que fundamenta a nossa visão de ser humano, deficiência, escola e trabalho educativo esteve consubstanciada em pressupostos teóricos que apregoam um projeto de educação, sociedade e ser humano afinados com os objetivos da transformação social e com a formação de um ser humano omnilateral. Um ser humano integralmente desenvolvido em suas potencialidades. Como teoria orientadora da prática educativa, consubstanciamo-nos na proposta pedagógico-metodológica e nos pressupostos filosóficos 
da Pedagogia Histórico-Crítica que, de acordo com Saviani (2012a, p. 30), “[...] impõe-se a tarefa de superar tanto o poder ilusório (que caracteriza as teorias não críticas) como a impotência (decorrente das teorias crítico-reprodutivistas) [...]", colocando nas mãos dos educadores, instrumentos de luta que viabilizem a realização de um poder efetivo, ainda que limitado. E, como teoria orientadora do desenvolvimento, fundamentamo-nos na abordagem Vygotskyana, a qual contribui com a defesa da intencionalidade pedagógica para a potencialização do desenvolvimento do ser humano.

Partindo dessa compreensão e subsidiados pelos dados coletados, elencamos um conjunto de categorias (concepções) consideradas básicas para a compreensão da temática discutida nesta pesquisa. A análise de elementos que nos remetem à determinada concepção de ser humano, deficiencia, escola, trabalho educativo, ensino-aprendizagem e professor, expressa nos documentos orientadores e nas entrevistas realizadas, nos possibilitou captar um conjunto de perspectivas teóricas que estão colocadas na articulação do trabalho administrativo-pedagógico do AEE operacionalizado pelas redes de ensino. Verifica-se que, na prática, existe uma mistura heterogênea e eclética de ideias advindas de contextos diferentes, podendo ser construídas durante o processo de escolarização do educador, durante sua própria experiência profissional ou ainda por assimilação do trabalho realizado por outros profissionais.

De acordo com Duarte (2007), nenhuma prática realiza de forma pura uma teoria pedagógica, isto é, mesmo que, inicialmente, a prática pedagógica apresente uma teoria como seu eixo central, fundamentalmente ela acaba incorporando elementos de outras teorias. Nesse sentido, por constatarmos não ser possível serem analisadas isoladamente, tomando como referência determinada concepção teórica, optamos por recorrer ao uso do termo miscelânea para denominarmos o conjunto das bases teóricas que subsidiam a organização pedagógica.

O exercício analítico nos permitiu construir duas categorias de análises. Identificamos um conjunto de bases teóricas que chamamos de Miscelânea Pragmática e outra que nomeamos de Miscelânea Crítica. A utilização dessas categorias possibilitou a compreensão do nosso objeto de estudo na sua totalidade, permitindo considerar as diversas manifestações teóricas e as integrando aos elementos que as aproximava e as constituía como uma abordagem, concepção e/ou tendência.

A categoria Miscelânea Pragmática pode ser identificada a partir de discursos que defendem a organização do trabalho pedagógico centrado em uma concepção educacional que se limita a um quadro naturalizante de estruturação do ser humano, isto é, enfatizando os aspectos físicos, biológicos e psicológicos e, desse modo, considerando o ser humano em abstrato, desvinculado de um engajamento contextual. Ou, de outro modo, discursos teóricos ancorados em uma concepção produtivista de educação, no qual sua função passa a estar relacionada a preparar mão de obra adequada para o mercado de trabalho, resultando, por conseguinte, em uma desvalorização do processo de ensino. Embasando o conjunto dessas perspectivas, apontamos os princípios teóricos da pedagogia tradicional ou da essência, da pedagogia nova ou da existência (escola nova e suas variantes) e da pedagogia tecnicista (sob o ponto de vista da produtividade e suas variantes). 
A categoria Miscelânea Crítica envolve os discursos que reconhecem o ser humano como um ser cultural, histórico e dialético e, nesse caso, explica o aprendizado humano a partir de sua natureza social, enfatizando o momento histórico e seus condicionantes sócio-político-econômicos. O termo miscelânea nos permitiu aproximar perspectivas teóricas que apresentam concepções próximas, embora suas especificidades sejam reconhecidas. Nesse viés, alinhamos a essa categoria os princípios teóricos das concepções crítico-reprodutivista e histórico-crítica.

Partindo dessa sistematização, os resultados da pesquisa revelaram, primeiramente, que o conjunto das bases teórico-pedagógicas que fundamentam a maior parte dos projetos pedagógicos no Brasil e, nesse contexto em específico, a atual Política Nacional de Educação Especial na Perspectiva da Educação Inclusiva para o AEE é uma miscelânea pragmática. Na sua totalidade, o conjunto dessas bases teórico-pedagógicas é orientado por uma pedagogia de tendência tecnicista, inspirada nos princípios de racionalidade, eficiência e produtividade, defendendo a educação como algo objetivo e operacional. Essa intencionalidade secundariza o processo de ensino e a preocupação em descobrir as formas adequadas de promover o desenvolvimento humano, inclusive das pessoas com deficiência. Dissemina valores que, ao dar ênfase na negação da perspectiva da totalidade para o processo de desenvolvimento humano, reforça, no campo educacional, na concepção de formação de professores e nos currículos escolares, uma ênfase aos conhecimentos tácitos, desarticulando a necessária relação entre teoria e prática, desvalorizando o conhecimento científico/teórico/acadêmico em razão do conhecimento adquirido no cotidiano. Esse é o caso das pedagogias do aprender a aprender, representadas inicialmente pela pedagogia nova e, atualmente, pela pedagogia das competências, do multiculturalismo e outras presentes nos atuais documentos nacionais sobre currículo (DUARTE, 2010).

Em segundo lugar, constatamos que, com base na caracterização ou não, de uma teoria pedagógica orientadora de suas atividades, as redes municipais vêm se organizando de forma distinta para atender às orientações da política inclusiva. Verificamos que a rede municipal de ensino, localizada no Estado de Goiás, ao buscar atender às orientações legais e operacionais da política inclusiva para a organização e estruturação do AEE, por não caracterizar, explicitamente, no seu plano de educação, uma concepção pedagógica específica, que apresente objetivos e metas estruturadas e intencionais para a orientação da sua prática educativa, centrou suas ações no que é enfatizado nos documentos orientadores no âmbito nacional, ou seja, priorizando as questões práticas, objetivas e operacionais, aproximando-se, assim, das bases teórico-pedagógicas anunciadas pela categoria miscelânea pragmática. E, de outro lado, a rede municipal de ensino localizada no Estado do Paraná, por defender um referencial teórico para a orientação do seu currículo, fundamentado por uma corrente teórico-filosófica crítica, seguindo as mesmas orientações legais e operacionais, demonstrou possibilidades diferenciadas de organização e estruturação das diretrizes do $\mathrm{AEE}$, de forma a não se subordinar às orientações mais gerais da política inclusiva. Tal organização aproximou essa rede de ensino aos princípios e concepções defendidos pelas bases teórico-pedagógicas expressadas pela categoria que nomeamos de miscelânea crítica. 
Desse modo, inferimos que ao seguirem, exclusivamente, as orientações das bases teórico-pedagógicas que fundamentam a atual política inclusiva para a organização e estruturação desse serviço, os municípios tendem a recorrer a medidas minimalistas e com objetivos utilitários e pragmáticos. Os argumentos que definem o ensino e a aprendizagem denotam uma concepção de desenvolvimento humano, ora espontaneísta, sustentada em um entendimento biológico, ora determinista, desconsiderando o papel privilegiado da mediação para o desenvolvimento de formas superiores de ampliação do conhecimento. Por conseguinte, as atividades desenvolvidas no âmbito administrativo e pedagógico priorizam o conhecimento pessoal, o não verbalizado, as relações sociais, a autonomia ou o uso de recursos técnicos e operacionais, esvaziadas de uma atividade de caráter formativo.

Partindo da perspectiva teórica anunciada pela categoria miscelânea pragmática, essa forma de organização se mostrou possibilitada, tanto pelos documentos municipais, quanto pela forma de operacionalização desse atendimento e pelos relatos das entrevistas realizadas. No Quadro 1, apresentamos de forma sintetizada os principais resultados:

Acreditamos que esses resultados se justificam devido ao ecletismo de referenciais teóricos e concepções distintas que em muitos contextos fundamentam as proposições apresentadas pelas teorias que compõem o grupo, aqui por nós nomeado de miscelânea pragmática. A filiação dessas perspectivas teóricas às bases liberais e economicistas, que remetem a educação para a lógica do custo-benefício, permeada pela valorização do menor gasto com maior frequência (GARCIA, 2006), acaba por reduzir tudo ao útil, produzindo um reducionismo pedagógico.

Compreendemos que a prática escolar e toda a organização do trabalho educativo estão sujeitas aos diferentes pressupostos sobre o papel da escola e da aprendizagem (SAVIANI, 2012a, 2012b). Tais pressupostos definem o objetivo, a natureza e a abrangência de suas ações. Assim, inferimos que, consubstanciados pelos princípios das bases teórico-pedagógicas anunciadas pela categoria miscelânea pragmática, o que se pode constatar nas ações desses âmbitos é que a organização administrativo-pedagógica para o atendimento especializado tem como ponto de partida a visão do ser humano como um ser natural, isto é, a educação é compreendida como tendo a função apenas de evitar influências que possam prejudicar o desenvolvimento natural do indivíduo. Por esse viés, ela restringe a educação do ser humano ao que é enfatizado nos enfoques do materialismo, pragmatismo e psicologismo pedagógico. ${ }^{6}$

6 O enfoque materialista pedagógico apresenta ênfase nos aspectos físicos (condições necessárias para que a existência humana possa situar-se no seu meio físico e tirar proveito das condições existentes), nesse viés "a determinação de objetivos e ideais educativos, a capacidade de previsão e o desencadeamento de um processo orientado, tornam-se impraticáveis" (SAVIANI, 2012b, p. 34). O enfoque no utilitarismo pedagógico (representado pelo pragmatismo) corre o risco de interpretar a educação do ser humano apenas em termos de utilidade biológica, sendo válida na medida em que for útil e fizer o ser humano progredir e adaptar-se às condições existentes. Enfatizando os aspectos psicológicos, a educação tende a se inscrever apenas no mundo interior do educando, tende a promover o desenvolvimento das potencialidades do educando evitando toda forma de coação por parte do educador, não obstante, para isso, apresenta ênfase no deixar fazer, secundar, preservar e proteger (SAVIANI, 2012b). 
Quadro 1 - Forma de organização administrativo-pedagógica subsidiada pelas bases teórico-pedagógicas alinhadas à categoria miscelânea pragmática.

\begin{tabular}{|c|c|}
\hline $\begin{array}{c}\hat{A M B I T O} \\
\text { ANALISADO }\end{array}$ & MISCELÂNEA PRAGMÁTICA \\
\hline \multirow{4}{*}{ Âmbito político } & $\begin{array}{l}\text { Evidencia um sistema paralelo de ensino dentro de uma mesma proposta político-pedagógica } \\
\text { (Educação Especial e Ensino regular). }\end{array}$ \\
\hline & $\begin{array}{l}\text { O não direcionamento e a falta de objetividade ao tratar de questões específicas que evidenciam } \\
\text { a concepção de Educação Especial na rede de ensino responsabilizam as unidades escolares e } \\
\text { os professores para a articulação das ações necessárias para a promoção desse serviço. }\end{array}$ \\
\hline & $\begin{array}{l}\text { O AEE é interpretado como sendo um programa destinado a compensar deficiências de } \\
\text { diferentes ordens. }\end{array}$ \\
\hline & $\begin{array}{l}\text { Ênfase nos aspectos quantitativos sobrepõe-se aos qualitativos, evidenciando uma preocupação } \\
\text { com o resultado, com o que está faltando e não no processo, ou seja, no que seria necessário } \\
\text { desenvolver para promover, harmoniosamente, as potencialidades do educando. }\end{array}$ \\
\hline \multirow{4}{*}{$\begin{array}{l}\text { Âmbito técnico- } \\
\text { científico }\end{array}$} & $\begin{array}{l}\text { A política de formação de professores fica sendo dependente das particularidades do ponto } \\
\text { de referência no qual o profissional se encontra; além de comprometer a universalidade do } \\
\text { conhecimento, distancia a possibilidade de um trabalho colaborativo entre o ensino comum e } \\
\text { a Ed. Especial. }\end{array}$ \\
\hline & $\begin{array}{l}\text { Cursos de formação com ênfase na Perspectiva Física e Biológica de estruturação e } \\
\text { desenvolvimento humano, com objetivos materialistas e utilitaristas. }\end{array}$ \\
\hline & $\begin{array}{l}\text { A distribuição de papéis (modulação) procura atender à demanda da rede e não o interesse do } \\
\text { profissional em atuar na Educação Especial e sua trajetória formativa. }\end{array}$ \\
\hline & Modulação de profissionais para realizar o AEE sem formação na área da Educação Especial. \\
\hline \multirow{4}{*}{$\begin{array}{l}\text { Âmbito } \\
\text { pedagógico }\end{array}$} & $\begin{array}{l}\text { São encaminhados para o atendimento na SRM alunos com deficiência e com dificuldades } \\
\text { acentuadas na aprendizagem, vinculadas ou não a uma causa específica. }\end{array}$ \\
\hline & $\begin{array}{l}\text { Não há proposta pedagógica definida que oriente a unidade escolar sobre os objetivos e } \\
\text { procedimentos a serem observados durante a elaboração do plano de AEE. A ênfase está em } \\
\text { possibilitar um roteiro para os procedimentos. }\end{array}$ \\
\hline & $\begin{array}{l}\text { As atividades pedagógicas realizadas no âmbito dos conteúdos escolares se restringem à } \\
\text { alfabetização. }\end{array}$ \\
\hline & $\begin{array}{l}\text { Falta de condições objetivas para troca de experiências entre os professores que atuam no AEE } \\
\text { com os professores regentes sobre as especificidades do atendimento especializado. }\end{array}$ \\
\hline \multirow{4}{*}{$\begin{array}{l}\text { Âmbito } \\
\text { administrativo }\end{array}$} & $\begin{array}{l}\text { Setor responsável pela educação especial com um quadro reduzido de técnicos em proporção } \\
\text { às atividades realizadas. }\end{array}$ \\
\hline & $\begin{array}{l}\text { Centralidade de ações relacionadas a questões administrativas que viabilizam a Educação } \\
\text { Especial no sistema de ensino, secundarizando a especificidade pedagógica. }\end{array}$ \\
\hline & $\begin{array}{l}\text { Possibilidades do atendimento na SRM ser realizado no horário da escolarização do educando, } \\
\text { deixando de ser complementar ou suplementar ao ensino comum, passando a ter uma } \\
\text { característica de substitutivo. }\end{array}$ \\
\hline & $\begin{array}{l}\text { Dificuldade em estabelecer uma rede de apoio municipal com atendimentos alternativos e } \\
\text { intersetoriais aos educandos com deficiência. }\end{array}$ \\
\hline
\end{tabular}

Fonte: Base de dados da pesquisa. 
Entendemos que, ao subsidiar-se nos pressupostos teóricos delineados pelo grupo de bases teórico-pedagógicas que alinhamos nesta categoria de análise, as secretarias de educação não apresentam condições de defender uma proposta político-pedagógica que expresse intencionalmente sua concepção de ensino-aprendizagem e que, ao mesmo tempo, tenha condições de orientar as unidades escolares a elaborarem seus projetos de ensino com vistas a defender o trabalho educativo como uma produção direta e intencional, preocupado em descobrir as formas mais adequadas de promover o desenvolvimento do ser humano. Subsidiados em Saviani (2013b), defendemos que o delineamento de uma prática educativa para desenvolver-se e possibilitar que os educandos se tornem agentes ativos no processo de desenvolvimento, necessita, fundamentalmente, ser orientada por um referencial teórico em uma perspectiva crítica e transformadora das relações de poder. Não se pode exercer uma ação desvinculada de uma intencionalidade. Para Saviani (2012b, p. 78):

A formulação de uma pedagogia (teoria educacional) integrará tanto os problemas como os conhecimentos (ultrapassando-os) na totalidade da práxis histórica onde receberão o seu pleno significado humano. A teoria referida deverá, pois, indicar os objetivos e meios que tornem possível a atividade comum intencional.

Contribuindo com a defesa da intencionalidade pedagógica para a potencialização do desenvolvimento humano, os aspectos fundamentais da abordagem Vygotskyana, que trata da concepção da pessoa com deficiência, determina que quaisquer aspectos que possam estabelecer a deficiência para o indivíduo tornam-se a condição básica para o surgimento de energia e capacidades para vencê-la (VYGOTSKY, 1997). Nessa compreensão, o processo educacional é fundamental para possibilitar a compensação do defeito no sentido de não atenuar as dificuldades, mas tensionar as forças necessárias a caminho da compensação.

[...] simultaneamente com o defeito, estão dadas também as tendências psicológicas de uma direção oposta; estão dadas as possibilidades de compensação para vencer o defeito e do que precisam, ante essas possibilidades se apresentam em primeiro plano no desenvolvimento da criança e devem ser incluídas no processo educacional como sua força motriz. Estruturar todo processo educativo segundo a linha das tendências naturais à supercompensação significa não atenuar as dificuldades que surgem no defeito. [...], mas tencionar todas as forças para sua compensação (VYGOTSKY, 1997, p. 32). ${ }^{7}$

Nesse contexto, a escola deve criar mecanismos que despertem a necessidade de transformar a deficiência em talento, compensando ou até supercompensando a deficiência. A compensação não está no sujeito, é de natureza social - está nas oportunidades que o grupo social oferece, nas condições concretas de inserção do sujeito em práticas culturais,

7 A tradução dessa citação do espanhol para o português é de nossa responsabilidade. 
mediatizadas pelos instrumentos e signos culturais. Assim, não são quaisquer apropriações que promovem esse desenvolvimento. Há a necessidade de um ensino intencional, sistematizado e com fins premeditados.

Ao discorrer acerca da organização do ensino especial, Vygotsky (1997) teceu duras críticas à clínica tradicional que se interessou basicamente em um enfoque quantitativo dos diagnósticos da deficiência, principalmente na distinção dos diferentes sintomas, possibilitando apenas diferenciá-los entre um quadro clínico e outro. Seu posicionamento contrário às formas como estavam organizados o ensino e as práticas em vigor alerta para que, embora seja reconhecida a necessidade de, em alguns casos, recorrer à utilização de meios completamente diferentes, fundamentalmente a essência do processo seria a mesma, ou seja, o mesmo ensino ministrado a crianças normais deve ser ministrado para as crianças com deficiência, com os mesmos objetivos e conteúdos.

Não devemos nos conformar mais com uma escola especial em que se aplique
simplesmente o programa reduzido da escola comum, nem com seus métodos
facilitados e simplificados. A escola especial se encontra diante da tarefa de uma
criação positiva, de gerar formas de trabalho próprias que respondam à peculiari-
dade de seus educandos [...]. Se renunciarmos à noção da criança deficiente como
uma semelhança diminuída da normal, indubitavelmente também devemos recu-
sar o conceito da escola especial como uma escola comum, prolongada no tempo
e com um material didático abreviado (VYGOTSKY, 1997, p. 33).

Nessa perspectiva, o autor adverte que a educação deveria basear-se na noção do potencial da natureza humana, compreendendo sua unidade e integridade orgânica e considerando que os obstáculos no desenvolvimento impostos pela deficiência podem servir como mola propulsora do desenvolvimento, por intermédio das possibilidades compensatórias.

Partindo desse entendimento, de outro modo, fundamentado pela perspectiva teórica anunciada pela categoria de análise miscelânea crítica, constatamos possibilidades distintas para a efetivação desse serviço. Em nossa pesquisa, verificamos que, em uma segunda possibilidade de intervenção, o direcionamento de um referencial teórico-crítico para a fundamentação das diretrizes operacionais do AEE apresenta aos sistemas de ensino uma possibilidade de atender aos pressupostos legais da política inclusiva, sem, contudo, esvaziar-se da sua especificidade pedagógica. O Quadro 2 exibe os principais resultados: 
Quadro 2 - Forma de organização administrativo-pedagógica subsidiada pelas bases teórico-pedagógicas alinhadas à categoria miscelânea crítica.

\begin{tabular}{|c|c|}
\hline $\begin{array}{c}\text { ÂMBITO } \\
\text { ANALISADO }\end{array}$ & MISCELÂNEA CRÍTICA \\
\hline \multirow[b]{3}{*}{ Âmbito político } & $\begin{array}{l}\text { Articulação do trabalho pedagógico especializado com as unidades escolares e com as ações } \\
\text { de outros órgãos intersetoriais (Saúde, da Assistência Social, do Trabalho, do Esporte e Lazer). }\end{array}$ \\
\hline & $\begin{array}{l}\text { Concepção de inclusão atenta às diferentes condições pedagógicas e metodológicas que } \\
\text { perpassam o atendimento educacional das pessoas com deficiência. }\end{array}$ \\
\hline & $\begin{array}{l}\text { A disponibilidade do AEE busca atender à especificidade do programa, voltado para a finalidade } \\
\text { ao qual se propõe e ofertado mediante a necessidade do público de atendimento. }\end{array}$ \\
\hline \multirow[b]{3}{*}{$\begin{array}{l}\text { Âmbito técnico- } \\
\text { científico }\end{array}$} & $\begin{array}{l}\text { Política de formação para todos os profissionais que atuam direta e indiretamente com os alunos } \\
\text { com deficiências, não sendo apenas para os profissionais que compõem o quadro de apoio } \\
\text { pedagógico especializado. }\end{array}$ \\
\hline & $\begin{array}{l}\text { A atuação na Educação Especial apresenta-se como uma possibilidade de atuação, podendo o } \\
\text { profissional se adequar a partir dos seus interesses individuais. }\end{array}$ \\
\hline & $\begin{array}{l}\text { Curso de formação numa perspectiva histórico-dialética, abordando especificações sobre a } \\
\text { reestruturação do atendimento, os processos de desenvolvimento da formação humana e os } \\
\text { movimentos de estudos científicos que orientam a proposta curricular da rede de ensino. }\end{array}$ \\
\hline \multirow{5}{*}{$\begin{array}{c}\text { Âmbito } \\
\text { pedagógico }\end{array}$} & $\begin{array}{l}\text { São encaminhados para o atendimento na SRM somente os alunos público-alvo da Educação } \\
\text { Especial. }\end{array}$ \\
\hline & $\begin{array}{l}\text { O processo de identificação dos alunos ao atendimento especializado é realizado pela equipe } \\
\text { escolar e pela equipe multifuncional, envolvendo uma análise detalhada e de conjunto, } \\
\text { considerando o desenvolvimento do educando no contexto escolar, tendo ou não diagnóstico } \\
\text { médico. }\end{array}$ \\
\hline & $\begin{array}{l}\text { Disponibilização de documentos orientadores que apresentam um itinerário para a realização } \\
\text { dos procedimentos operacionais e sobre os aspectos pedagógicos que devem ser observados. }\end{array}$ \\
\hline & $\begin{array}{l}\text { As ações desenvolvidas nas SRM são específicas do AEE e a intencionalidade da prática educativa } \\
\text { está voltada para a contemplação dos aspectos fundantes do desenvolvimento humano (Funções } \\
\text { Psicológicas Superiores) apresentando, paralelamente, a observância de meios para oferecer } \\
\text { subsídios para a apropriação e elaboração de conceitos e de conteúdos escolares que se encontram } \\
\text { em defasagem para o aluno. }\end{array}$ \\
\hline & $\begin{array}{l}\text { Condições objetivas para a troca de informações e experiências entre os professores do AEE, } \\
\text { professores regentes e familiares do educando, se efetivando por meio da garantia da hora/ } \\
\text { atividade. }\end{array}$ \\
\hline \multirow{4}{*}{$\begin{array}{c}\text { Âmbito } \\
\text { administrativo }\end{array}$} & $\begin{array}{l}\text { As atribuições dos profissionais que atuam no setor responsável pela Educação Especial estão } \\
\text { relacionadas com sua formação e/ou com as ações de acompanhamento das práticas educativas } \\
\text { no contexto escolar. }\end{array}$ \\
\hline & $\begin{array}{l}\text { As demandas ligadas ao aspecto administrativo da educação especial ficam sob a responsabilidade } \\
\text { dos setores do âmbito pedagógico, administrativo e financeiro, transversalizando as ações da } \\
\text { EEs dentro da secretaria da educação. }\end{array}$ \\
\hline & $\begin{array}{l}\text { Constituição de espaços próprios para o acompanhamento e assessoramento da acessibilidade } \\
\text { curricular aos alunos que apresentam condições de comunicação e sinalização diferenciada. }\end{array}$ \\
\hline & $\begin{array}{l}\text { A rede de apoio articulada com outras instituições (Saúde, da Assistência Social, do Trabalho, } \\
\text { do Esporte e Lazer), de forma intersetorial. }\end{array}$ \\
\hline
\end{tabular}

Fonte: Base de dados da pesquisa. 
Essa possibilidade de organização e estruturação se justifica pelo fato de que, em sua essência, as teorias que compõem a categoria miscelânea crítica defendem a concepção de que o ser humano não se forma isoladamente, mas em um contexto em que devem ser reconhecidos seus condicionantes natural, cultural, histórico-dialético e, prioritariamente, por defender uma organização do ensino de forma a garantir que os conhecimentos ultrapassem o pragmatismo e o operacionismo, tão presentes nas bases teórico-pedagógicas que fundamentam a política nacional de educação especial/inclusiva.

Inferimos que as perspectivas teóricas alinhadas a essa categoria de análise apontam para os sistemas de ensino direcionamentos que induzem a uma organização institucional atenta não simplesmente à transmissão do saber, mas também aos métodos e às formas de planejamento de todo o conjunto das atividades escolares, de forma que possibilitem a real assimilação do saber escolar. Essa defesa é sintetizada por Saviani (2013b, p. 17), conforme destacamos:

\begin{abstract}
[...] para existir a escola não basta a existência do saber sistematizado. É necessário viabilizar as condições de sua transmissão e assimilação. Isso implica dosá-lo e sequenciá-lo de modo que a criança passe gradativamente do seu não domínio ao seu domínio. Ora, o saber dosado e sequenciado para efeitos de sua transmissão-assimilação no espaço escolar, ao longo de um tempo determinado, é o que nós convencionamos chamar de "saber escolar".
\end{abstract}

A compreensão de que o desenvolvimento é percebido como entrelaçado às práticas culturais e educativas, incluindo, necessariamente, o processo de aprendizagem, possibilita posturas mais homogêneas e coerentes, tanto em relação às ações desenvolvidas nas unidades escolares, quanto em relação aos encaminhamentos direcionados pelas Secretarias de Educação, inclusive no que se refere à articulação favorável entre a secretaria da educação com as outras instituições, de forma intersetorial.

\title{
CONSIDERAÇÕES FINAIS
}

A análise desenvolvida nesta pesquisa nos remeteu a uma contextualização das transformações pelas quais vem passando o atendimento educacional às pessoas com deficiências em decorrência das mudanças políticas, sociais, econômicas e culturais, evidenciando que as formas de organização do serviço da Educação Especial na rede regular de ensino estão em consonância com o plano hegemônico e com determinações materiais que sustentam os interesses do sistema capitalista. Sendo assim, o processo de estruturação e implantação das políticas educacionais nos sistemas de ensino não é mecânico. O processo não está pronto, fechado. Ele é dinâmico e se materializa integrando tanto os problemas como os conhecimentos.

As nossas análises revelaram que a categoria miscelânea pragmática, em síntese, compreende as correntes ou tendências que apreciam e defendem a forma como as coisas 
são ditas e experienciadas em detrimento de um conhecimento mais amplo, intencional, objetivo, complexo, científico, artístico e filosófico. Partindo dessa fundamentação, a organização do atendimento para crianças com deficiências tem desconsiderado o aspecto psíquico e histórico-cultural em que as mesmas estão inseridas. Assim, a educação é debilitada por um trabalho fragmentado e alienado, não tocando em aspectos vitais e essenciais ao ser humano, inclusive no que se refere às condições objetivas para que os educadores possam conjecturar metodologias e práticas pedagógicas que atendam ao aluno concreto que se encontra na sala de aula, levando em conta sua realidade física, biológica, psicológica, cultural e social.

Desse modo, diante da precarização que está posta sobre a intencionalidade pedagógica, não podemos deixar de demarcar o contexto político em que esta pesquisa foi realizada e as projeções das atuais medidas apresentadas pelo governo brasileiro, visto que evidenciam mais um golpe da classe hegemônica contra o povo e contra uma educação mais progressista, potencializando, por meio de leis e decretos, elementos que fortalecem e induzem à organização do trabalho pedagógico a partir dos princípios defendidos pelas pedagogias hegemônicas (neotecnicismo, neoescolanovismo, neoprodutivismo etc.), alinhadas, aqui, na categoria miscelânea pragmática. Entre essas medidas, destacamos o "Novo Regime Fiscal" instituído no país por intermédio da Proposta de Emenda à Constituição (PEC) $n^{\circ} .55$, de 2016, que limitou o aumento dos gastos públicos à variação da inflação por 20 anos; a reforma do Ensino Médio via Medida Provisória (MP), que promove uma mudança de currículo nessa fase escolar, dividindo a formação em apenas cinco áreas do conhecimento (linguagens, matemática, ciências naturais, ciências humanas e formação técnica); o Projeto de Lei "Escola sem Partido", ou "Lei da Mordaça" que, entre outras questões, estabelece uma série de regras para controlar a atuação do professor em sala de aula, praticamente impedindo-o de promover um debate crítico de ideias com os alunos; e as interferências dessa política nos princípios delineados pela atual Base Nacional Comum curricular (BNCC), que restringe o conceito de educação e se alinha contra uma educação mais progressista, reduzindo as oportunidades educacionais dos estudantes e a autonomia docente em detrimento dos interesses capitalistas.

Essas medidas revelam projeções que precarizarão ainda mais o campo da Educação Especial e as possibilidades de um ensino comprometido com uma perspectiva superadora de desenvolvimento do ser humano. Defendemos que a organização do trabalho pedagógico deve ser marcada pela análise, reflexão e compreensão do fazer pedagógico crítico, com o intuito de intervir e visar mudanças, sendo possível, somente, a partir de uma orientação didático-metodológica fundamentada pelos princípios anunciados pelas teorias da categoria miscelânea crítica.

Por estarem comprometidas e defenderem uma educação que tenha como objetivo a elevação do nível de desenvolvimento dos educandos, com vistas às esferas mais superiores e possíveis neste momento histórico, tais teorias promovem a organização de um trabalho pedagógico que possibilita condições para que os alunos, tendo deficiência ou não, se reconheçam como sujeitos conscientes de sua realidade histórica e social e, portanto, responsáveis por sua transformação, tanto no âmbito objetivo quanto subjetivo. 
Assim, concluímos que o direito à educação não possibilita, por si só, que a pessoa com deficiência tenha um acesso equitativo à cultura humana. Ao organizar e estruturar ações para a operacionalização do AEE nos sistemas de ensino é preciso pensar na importância da didática (como ensinar e como aprender), apropriando-se de teorias que expliquem o desenvolvimento humano e orientem a prática educativa, considerando o caráter histórico do ser humano; pensar na organização do ensino (como conteúdo, espaço, tempo e procedimentos); e, por fim, pensar nas mediações estabelecidas no contexto escolar, a fim de que tais garantias não tenham como consequência uma inclusão que exclui.

No entanto, demarcamos que essas ações não estão restritas unicamente a políticas internas das redes de ensino, porque envolvem, de forma intensa, articulada e ampla, condicionantes que se associam à concepção de sociedade, educação, trabalho educativo, escola e de ser humano apregoados pela forma de organização social global. E isso nos convoca a questionar, denunciar e lutar contra a atual forma de organização social injusta, sobre o atual papel da educação com vistas à manutenção de uma sociedade de classes, sobre os interesses capitalistas imbuídos nos cursos de formação de professores e sobre a concepção de desenvolvimento humano alinhado com as formas produtivas do trabalho.

Em síntese, frisamos a importância do AEE como uma conquista adquirida na trajetória da Educação Inclusiva e ressaltamos que a defesa que fazemos é de uma organização do trabalho pedagógico no AEE comprometido com o objetivo de possibilitar ao educando com deficiência condição de se reconhecer como sujeito consciente de sua realidade histórica e social. Contudo, alertamos que a superação das práticas fragmentadas, fetichizadas e alienadas, sejam da prática social global e/ou da prática educacional no AEE, poderá oferecer melhores contribuições se estiver vinculada a uma teoria da práxis crítica, transformadora das relações de poder.

\section{REFERÊNCIAS}

BRASIL. Declaração de Salamanca e linha de ação sobre necessidades educativas especiais. Brasília: UNESCO, 1994.

. Conselho Nacional de Educação. Câmara de Educação Básica. Parecer nº 17, de 3 de junho de 2001. Brasília, 2001a.

. Conselho Nacional de Educação/Câmara de Educação Básica. Resolução nº. 2, de 11 de setembro de 2001. Institui diretrizes operacionais para a Educação Especial na Educação Básica. Brasília, DF, 2001 .

. Ministério da Educação. Política Nacional de educação especial na perspectiva da educação inclusiva. Brasília, 2008.

. Resolução $n^{0} .4$ de 2 de outubro de 2009. Institui Diretrizes Operacionais para 
o Atendimento Educacional Especializado na Educação Básica, modalidade Educação Especial. Brasília, DF: Ministério da Educação, Conselho Nacional de Educação, Câmara de Educação Básica, 2009.

. Ministério da Educação. Secretaria de Educação Especial. Manual de orientação: programa de implantação de salas de recursos multifuncionais. Brasília, DF: MEC: SEESP, 2010a.

. Nota técnica $\mathbf{n}^{\mathbf{0}} .11$ de 7 de maio de 2010. Orientações para a Institucionalização na Escola, da oferta do Atendimento Educacional Especializado - AEE em Sala de Recursos Multifuncionais. Brasília, DF: Ministério da Educação, Secretaria de Educação Especial, 2010b.

. Decreto no 7.611 de 17 de novembro de 2011. Dispõe sobre a Educação Especial, o atendimento educacional especializado e dá outras providências, 2011.

. Plano Nacional de Educação - Lei n ${ }^{\circ} .13 .005$, de 25 de junho de 2014.

DUARTE, N. Sobre o construtivismo. Campinas: Autores Associados, 2000.

. Teorias Pedagógicas (Porque estudá-las), 2007, flv. Disponível em: < $\underline{\text { https:// }}$ www.youtube.com/watch? $\mathrm{v}=\mathrm{uCHSUjiQjPQ}>$. Acesso em: 15 jun. 2016.

. O debate contemporâneo das teorias pedagógicas. In: MARTINS, L. M.; DUARTE, N. Formação de Professores: limites contemporâneos e alternativas necessárias. São Paulo: Cultura Acadêmica, 2010, p. 33-49.

GARCIA, R. M. C. Políticas para a educação especial e as formas organizativas do trabalho pedagógico. Rev. Bras. de Ed. Esp. Marília, v. 12, n. 3, set./dez. 2006, p. 299-316.

KASSAR, M. de C. M. Percursos da constituição de uma política brasileira de educação especial inclusiva. Rev. Bras. Ed. Esp. Marília, v. 17, p. 41-58, mai./ago. 2011. Edição Especial.

SÁNCHEZ-GAMBOA, S. Projetos de pesquisa, fundamentos lógicos: a dialética entre perguntas e respostas. Chapecó: Argos, 2013.

SAVIANI, D. As concepções pedagógicas na história da educação brasileira. Campinas, UNICAMP, Projeto "20 anos do HISTEDBR", 2005. Disponível em: <http://www. joinville.udesc.br/portal/professores/maria/index.php?pg=materiais $>$. Acesso em: 12 dez. 2014. 
. Escola e democracia, 42. ed. Campinas: Autores Associados, 2012a.

. Educação brasileira: estrutura e sistema, 11. ed. Campinas: Autores Associados, 2012 b.

. História das idéias pedagógicas no Brasil, 4. ed. Campinas: Autores Associados, $2013 a$.

. Pedagogia histórico-crítica: primeiras aproximações, 11. ed. rev. Campinas: Autores Associados, 2013b.

SAVIANI, D.; DUARTE, N. A formação humana na perspectiva histórico-ontológica. Revista Brasileira de Educação. Caxambu, v. 15, n. 45, p. 422-590, set./dez. 2010.

SHIROMA, E. O.; MORAIS, M. C. M.; EVANGELISTA, O. Política Educacional, 4. ed. Rio de Janeiro: Lamparina, 2007.

SILVA, R. H. dos R. Tendências teórico-filosóficas das teses em educação especial desenvolvidas nos cursos de doutorado em educação e educação física do estado de São Paulo (1985-2009), 2013. Tese (Doutorado em Educação) - Faculdade de Educação, Unicamp. Unicamp/SP, 2013.

VYGOTSKY, L. S. Obras escogidas: fundamentos de defectologia. Tomo V. Habana: Editorial Pueblo y Educación, 1997.

\section{Dados dos Autores:}

IVONE Rodrigues dos SANTOS

Doutoranda em Educação pela Universidade Estadual de Campinas. Coordenadora do Centro de Formação dos Profissionais da Educação da rede municipal de Aparecida de Goiânia e professora efetiva PIV na Rede Estadual de Educação de Goiás. Aparecida de Goiânia/ GO - Brasil. ivonesantospsico@hotmail.com

RÉGis Henrique dos Reis Silva

Doutor em Filosofia e História da Educação pela Universidade Estadual de Campinas. Professor e chefe do Departamento de Filosofia e História da Educação da Faculdade de Educação da Universidade Estadual de Campinas. Desde setembro de 2016 é Editor da Revista Revista Histedbr on-line.Campinas/SP - Brasil. regishsilva@gmail.com

Submetido em: 1-6-2018

Aceito em: 29-3-2019 